Supporting Information for

\title{
Base-Free Iridium-Catalyzed Hydrogenation of Esters and Lactones
}

Timothy P. Brewster, ${ }^{\dagger}$ Nomaan M. Rezayee,,${ }^{\ddagger}$ Zuzana Culakova,${ }^{\dagger}$ Melanie S. Sanford, ${ }^{\ddagger}, *$ and

\author{
Karen I. Goldberg ${ }^{\dagger, *}$ \\ ${ }^{\dagger}$ Department of Chemistry, University of Washington, Seattle, WA 98195-1700 \\ ${ }^{\ddagger}$ Department of Chemistry, University of Michigan, 930 North University Ave., Ann Arbor, MI 48109
}

Email: goldberg@chem.washington.edu,mssanfor@umich.edu, 


\section{Table of Contents}

Page S3. Experimental Details

Page S4. Representative Procedures for Hydrogenation of Esters and Lactones

Page S6. ESI-MS Evidence for Oligomer Formation

Page S9. Time Course of Ethyl Acetate Hydrogenation

Page S10. Time Course of Hexyl Formate Hydrogenation in DME Solvent

Page S10. References 


\section{Experimental Details}

\section{Materials and Methods:}

Procedures were performed using standard Schlenk techniques or in a nitrogen glovebox unless otherwise specified. Tetrahydrofuran was dried on a Grubbs-type solvent purification system. ${ }^{1}$ All other liquid reagents and solvents were purchased from commercial sources and thoroughly degassed prior to use. [Cp* $\left.\operatorname{Ir}(\mathrm{bpy}-\mathrm{OMe}) \mathrm{OH}_{2}\right][\mathrm{OTf}]_{2}(\mathbf{1}),{ }^{2}\left[\mathrm{Cp}^{*} \operatorname{Ir}(\mathrm{bpy}) \mathrm{OH}_{2}\right][\mathrm{OTf}]_{2}$ (2), ${ }^{3}$ and $\left[\mathrm{Cp}^{*} \operatorname{Ir}(\mathrm{bpy}-\mathrm{COOMe}) \mathrm{OH}_{2}\right][\mathrm{OTf}]_{2}(3)^{4}$ were synthesized according to literature procedures. Authentic samples of the cyclic ethers tetrahydropyran, ${ }^{5} 2$-methyl tetrahydropyran ${ }^{6}$ and oxepane $^{7}$ were synthesized by dehydration of the corresponding diol in the presence of Nafion$\mathrm{H}^{8}{ }^{8}$ Ethyl acetate, ethyl formate, methyl acetate, methyl benzoate, and methyl pivalate were obtained from commercial sources and dried according to literature procedures prior to use. ${ }^{9}$ Products were verified by comparison with literature spectra. Other reagents were purchased from commercial sources and utilized without further purification. Deuterated solvents $\left(\mathrm{CDCl}_{3}\right.$, $\mathrm{CD}_{2} \mathrm{Cl}_{2}$, and $\mathrm{CD}_{3} \mathrm{CN}$ ) were obtained from Cambridge Isotope Laboratories and used as-received. ${ }^{1} \mathrm{H}$ NMR spectra were recorded on a $300 \mathrm{MHz}$ Bruker, $500 \mathrm{MHz}$ Bruker, or $500 \mathrm{MHz}$ Varian spectrometer using a $90^{\circ}$ pulse angle and a 35 s relaxation delay (unless otherwise specified) and referenced to the residual solvent peak. ${ }^{10}{ }^{13} \mathrm{C}$ NMR spectra were recorded on a $500 \mathrm{MHz}$ Bruker spectrometer and referenced to the residual solvent peak. ${ }^{10}$ Electrospray ionization mass spectrometry was performed by Loren Kruse at the University of Washington. Elemental analysis was obtained from the CENTC Elemental Analysis Facility at the University of Rochester, funded by NSF CHE-0650456.

\section{Synthesis of 2-(N-fmoc-amino)ethyl formate (E12)}

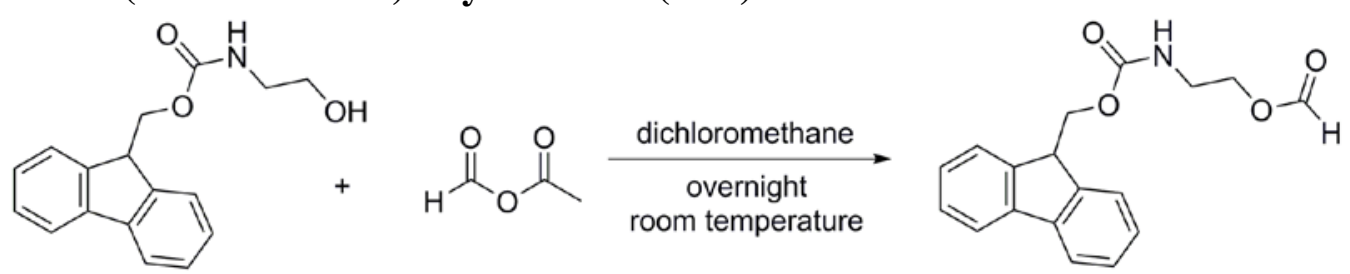

Acetic-formic anhydride ${ }^{11}$ was synthesized by the addition of $2.7 \mathrm{~mL}$ formic acid (97\%) to 5.9 $\mathrm{mL}$ of acetic anhydride under inert atmosphere. This material was stored in a Schlenk flask under $\mathrm{N}_{2}$ and was used without further purification. 2-(N-Fmoc-amino)ethanol was synthesized as described in the literature. ${ }^{12}$ In a round-bottom flask, $1.507 \mathrm{~g}(5.32 \mathrm{mmol})$ of 2-(N-fmocamino)ethanol was dissolved in $60 \mathrm{~mL}$ dichloromethane. Formic-acetic anhydride (3 mL, large excess) was added via syringe. The reaction was stirred under air overnight at room temperature. The resulting solution was then extracted with $3 \times 60 \mathrm{~mL}$ saturated $\mathrm{Na}_{2} \mathrm{CO}_{3}$. The organic layer was dried over $\mathrm{Na}_{2} \mathrm{SO}_{4}$, and the volatiles were removed. The crude product was then purified by flash chromatography and isolated as a white powder (silica gel, 70:30 hexanes:ethyl acetate, $\mathrm{R}_{\mathrm{f}}$ $=0.4) .{ }^{1} \mathrm{H}$ NMR $\left(300 \mathrm{MHz}, \mathrm{CD}_{2} \mathrm{Cl}_{2}\right) \delta 8.06(\mathrm{~s}, 1 \mathrm{H}), 7.78(\mathrm{~d}, J=7.5 \mathrm{~Hz}, 2 \mathrm{H}), 7.60(\mathrm{~d}, J=7.4 \mathrm{~Hz}$, 2H), 7.41 (t, $J=7.4 \mathrm{~Hz}, 2 \mathrm{H}$ ), 7.32 (td, $J=7.4,1.3 \mathrm{~Hz}, 2 \mathrm{H}), 5.07$ (s, 1H), 4.41 (d, $J=6.8 \mathrm{~Hz}$, 2H), $4.22(\mathrm{~m}, 3 \mathrm{H}), 3.46(\mathrm{q}, J=5.7 \mathrm{~Hz}, 2 \mathrm{H}) .60$ s relaxation delay employed to obtain proper integration of formate proton. ${ }^{13} \mathrm{C}$ NMR $\left(126 \mathrm{MHz}, \mathrm{CD}_{2} \mathrm{Cl}_{2}\right) \delta 161.13,156.56,144.40,141.68$, 128.04, 127.41, 125.38, 120.32, 66.98, 63.17, 47.65, 40.30. Elemental Analysis: Calculated C 69.44, H 5.50, N 4.50. Measured C 69.18 H 5.58 N 4.45. Yield: 874 mg (53.0\%). Melting point: $111.7-113.0^{\circ} \mathrm{C}$. 


\section{General Procedures for Hydrogenation}

High pressure hydrogenation reactions were carried out in 30 or $45 \mathrm{~mL}$ Parr Instruments 5000 Multiple Reactor system vessels fitted with a PTFE liners at the stated hydrogen pressure. Products were quantified by ${ }^{1} \mathrm{H}$ NMR spectroscopy against an internal standard (toluene, $\delta 2.36$ in $\mathrm{CDCl}_{3}$ or $\delta 2.34$ in $\mathrm{CD}_{2} \mathrm{Cl}_{2}$ ) or by gas chromatography (GC-FID) against an internal standard of 1,4-dioxane. Product identities were confirmed by spiking the reaction mixture with commercial or independently prepared samples. GC-FID analysis was performed on an Agilent Technologies 7890A GC system using an Agilent Technologies DB-FFAP column. Samples were prepared by volumetrically diluting reaction aliquots to $5 \mathrm{~mL}$ with acetone. Substrates analyzed by GC-FID: hexyl formate (E6), isopropyl formate (E7), tert-butyl formate (E8), phenyl formate (E9), benzyl formate (E10), anisyl formate (E11), $\gamma$-butyrolactone (L1), $\gamma$ valerolactone (L2). Reaction mixtures containing 2-(N-fmoc-amino)ethyl formate were analyzed by ${ }^{1} \mathrm{H}$ NMR spectroscopy with a 60 s relaxation delay.

\section{A) Neat Reactions}

In a nitrogen-filled glovebox, $10.3 \mathrm{mg}(0.012 \mathrm{mmol})$ of catalyst 1 was weighed into a glass vial and dissolved in $6 \mathrm{~mL}$ of substrate. $2 \mathrm{~mL}$ aliquots of the resulting yellow solution were dispensed into each of three PTFE-lined Parr reactors containing PTFE-covered stir bars. The reactors were then sealed, removed from the glovebox, briefly purged with $\mathrm{H}_{2}$, and pressurized. The reaction vessels were heated to the specified temperature for the specified reaction time. Reactors were placed in a cold bath at either $0{ }^{\circ} \mathrm{C}$ or $-84{ }^{\circ} \mathrm{C}$ to cool. Excess pressure was vented and the reactors were shaken and then opened in air. Products were then analyzed by either ${ }^{1} \mathrm{H}$ NMR spectroscopy or GC-FID.

Alternatively, $3.4 \mathrm{mg}(0.0040 \mathrm{mmol})$ catalyst 1 was weighed directly into the PTFE liner, and 2 $\mathrm{mL}$ substrate was then added to the reaction vessel. The remaining procedure is as above.

\section{B) Neat Reactions with Acid Additive}

In a nitrogen-filled glovebox, $\mathrm{Sc}(\mathrm{OTf})_{3}(19.7 \mathrm{mg}, 0.0400 \mathrm{mmol})$ was weighted into each of three PTFE Parr reactor liners. Liners were equipped with stir bars and inserted into the reaction vessels. In a glass vial, catalyst $1(10.3 \mathrm{mg}, 0.0040 \mathrm{mmol})$ was weighed into a glass vial and dissolved in $6 \mathrm{~mL}$ of substrate. From the resulting yellow solution, $2 \mathrm{~mL}$ aliquots were dispensed into each of three PTFE-lined Parr reactors containing PTFE-covered stir bars. Reactors were then sealed, removed from the glovebox, briefly purged with $\mathrm{H}_{2}$, and pressurized at room temperature. The reaction vessels were heated to the specified temperature for the specified reaction time. Reactors were placed in a cold bath at either $0{ }^{\circ} \mathrm{C}$ or $-84{ }^{\circ} \mathrm{C}$ to cool. Excess pressure was vented, and the reactors were shaken and opened in air. Products were then analyzed by either ${ }^{1} \mathrm{H}$ NMR spectroscopy or GC-FID. 


\section{C) In Solvent with Acid Additive}

In a nitrogen-filled glovebox, catalyst 1 (4.3 mg, $0.0050 \mathrm{mmol})$ and $\mathrm{Sc}(\mathrm{OTf})_{3}(2.5 \mathrm{mg}, 0.0050$ $\mathrm{mmol}$ ) were weighed into each of three PTFE Parr reactor liners. Liners were equipped with stir bars and inserted into the reaction vessels. Anhydrous dimethoxyethane (Acros, $1 \mathrm{~mL}$ ) and substrate $(1.0 \mathrm{mmol})$ was dispensed into each reactor. Reactors were then sealed, removed from the glovebox, briefly purged with $\mathrm{H}_{2}$, and pressurized at room temperature. The reaction vessels were heated to the specified temperature for the specified reaction time. Reactors were placed in a cold bath at either $0{ }^{\circ} \mathrm{C}$ or $-84{ }^{\circ} \mathrm{C}$ to cool. Excess pressure was vented, and the reactors were shaken and opened in air. Products were then analyzed by either ${ }^{1} \mathrm{H}$ NMR spectroscopy or GCFID.

\section{D) In Solvent, No Acid}

In a nitrogen-filled glovebox, catalyst $1(4.3 \mathrm{mg}, 0.0050 \mathrm{mmol})$ was weighed into each of three PTFE Parr reactor liners. Liners were equipped with stir bars and inserted into the reaction vessels. Anhydrous dimethoxyethane (Acros, $1 \mathrm{~mL})$ and substrate $(1.0 \mathrm{mmol})$ was dispensed into each reactor. Reactors were then sealed, removed from the glovebox, briefly purged with $\mathrm{H}_{2}$, and pressurized at room temperature. The reaction vessels were heated to the specified temperature for the specified reaction time. Reactors were placed in a cold bath at either $0{ }^{\circ} \mathrm{C}$ or $-84{ }^{\circ} \mathrm{C}$ to cool. Excess pressure was vented and the reactors were shaken and opened in air. Products were then analyzed by either ${ }^{1} \mathrm{H}$ NMR spectroscopy or GC-FID. 
ESI-MS analysis of oligomeric Products: Electrospray ionization mass spectrometry was performed by Loren Kruse at the University of Washington. All samples prepared for ESI-MS were obtained from reactions containing $2 \mathrm{mM}$ catalyst in $2 \mathrm{~mL}$ substrate heated at $100{ }^{\circ} \mathrm{C}$ for 65 hours (Procedure A).

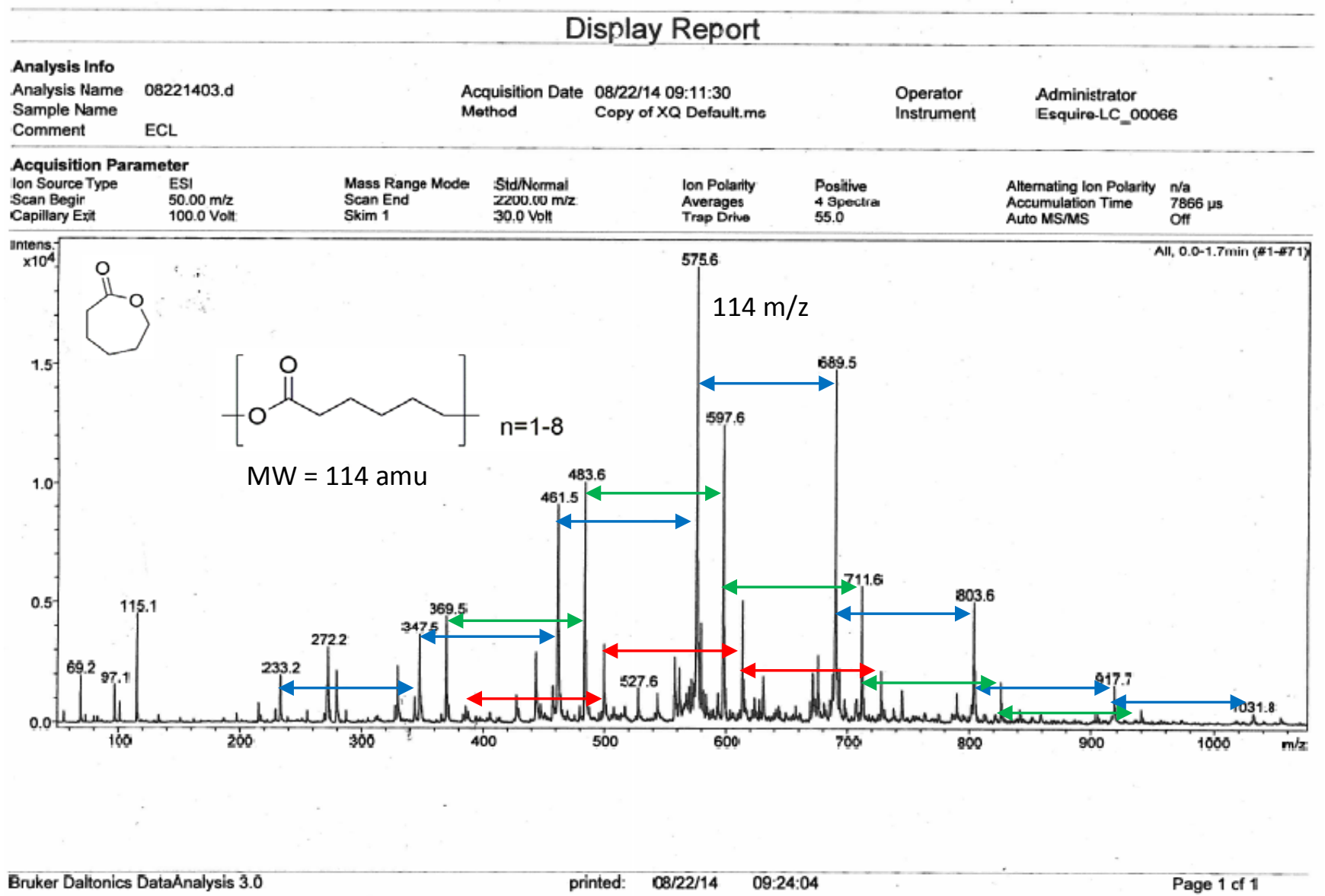

Figure S1. Oligomeric products from hydrogenation of $\varepsilon$-caprolactone. 


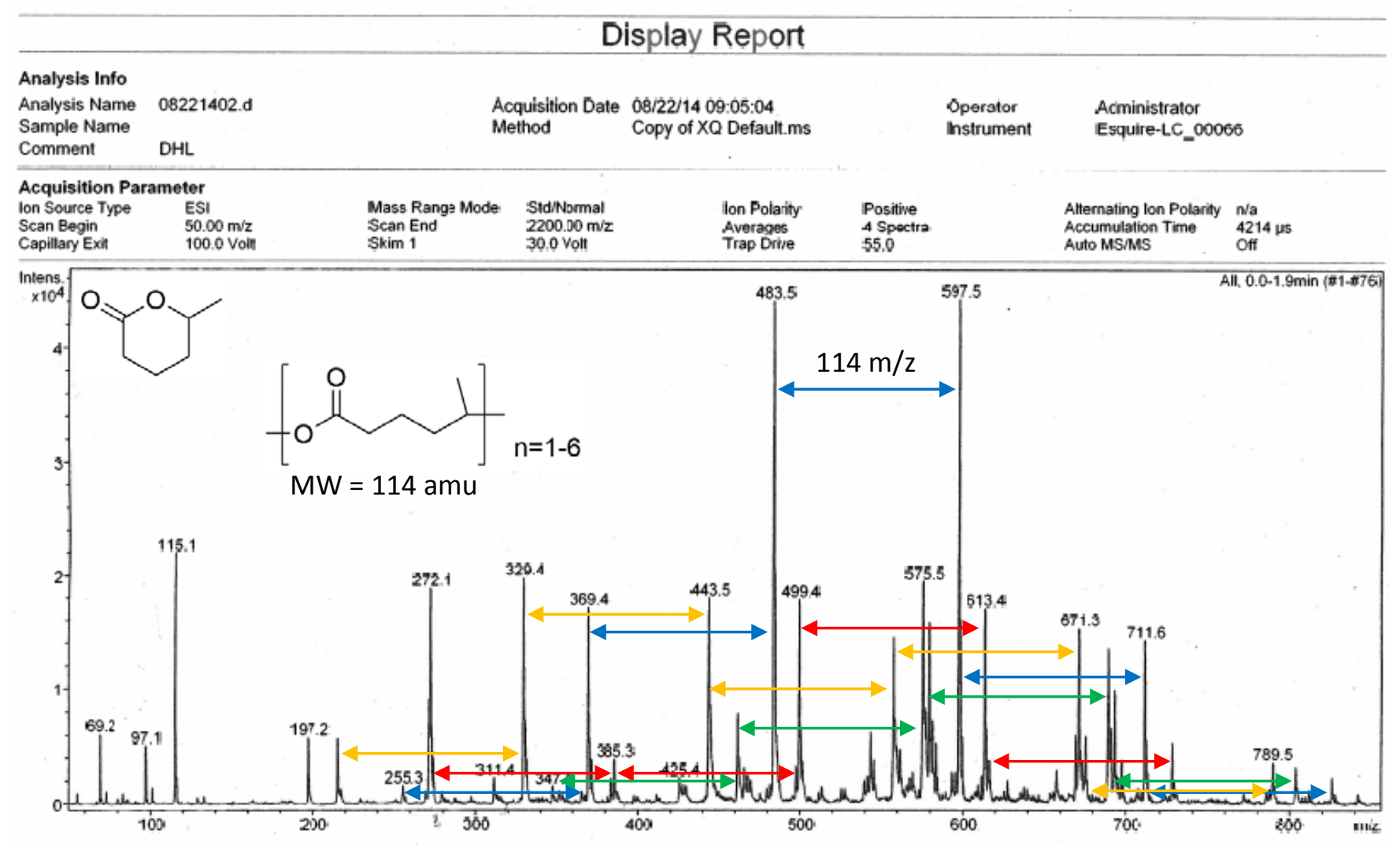

Bruker Daltonics DataAnalysis 3.0

printed: $\quad 0 \% / 22 / 14 \quad 00: 24: 20$

Page 1 of 1

Figure S2. Oligomeric products from hydrogenation of $\delta$-caprolactone. 


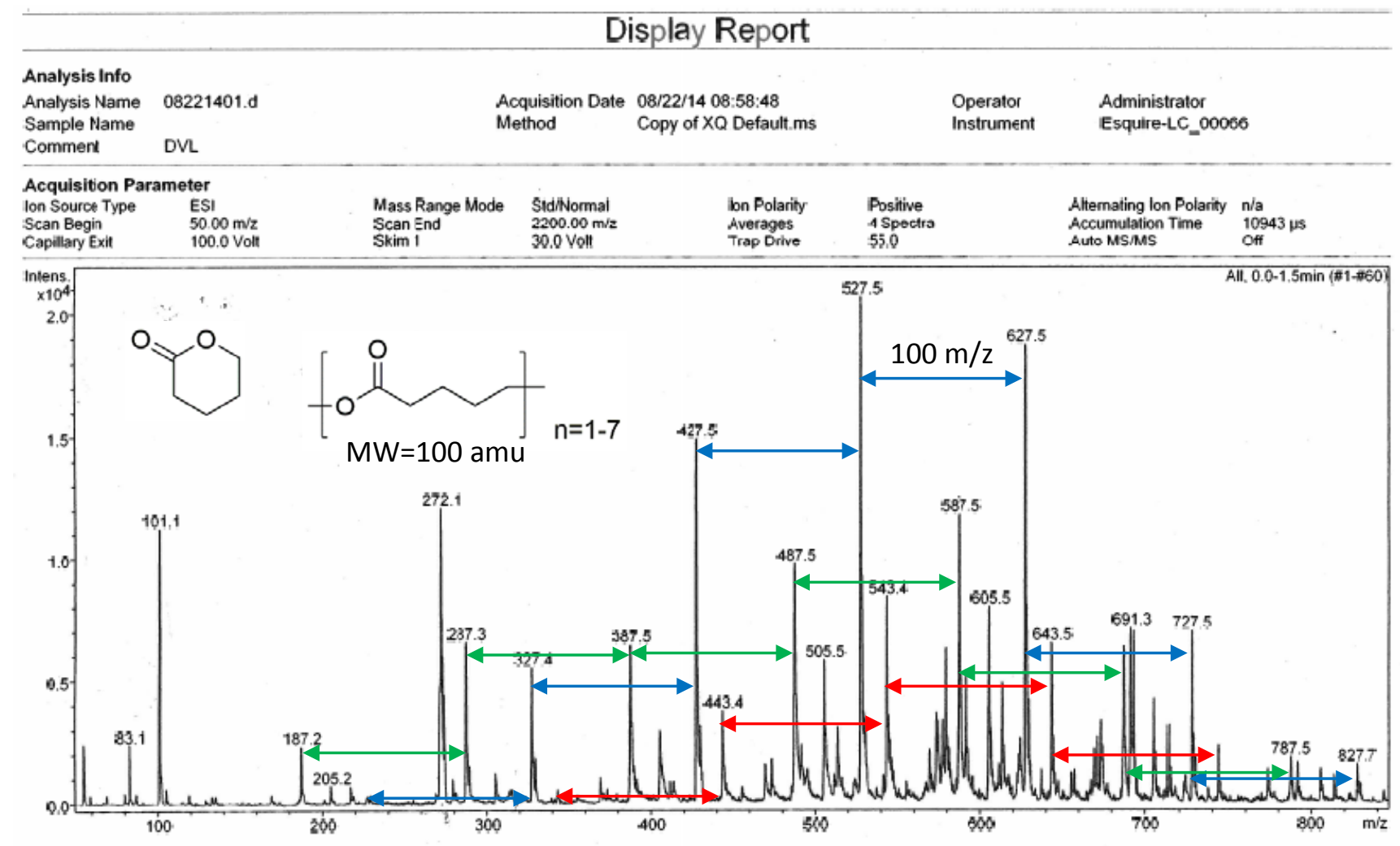

Bruker Daltonics DataAnalysis 3.0

printed: $\quad 68 / 22 / 14 \quad 09: 24: 35$

Page $1 \mathrm{cf}$

Figure S3. Oligomeric products from hydrogenation of $\delta$-valerolactone. 


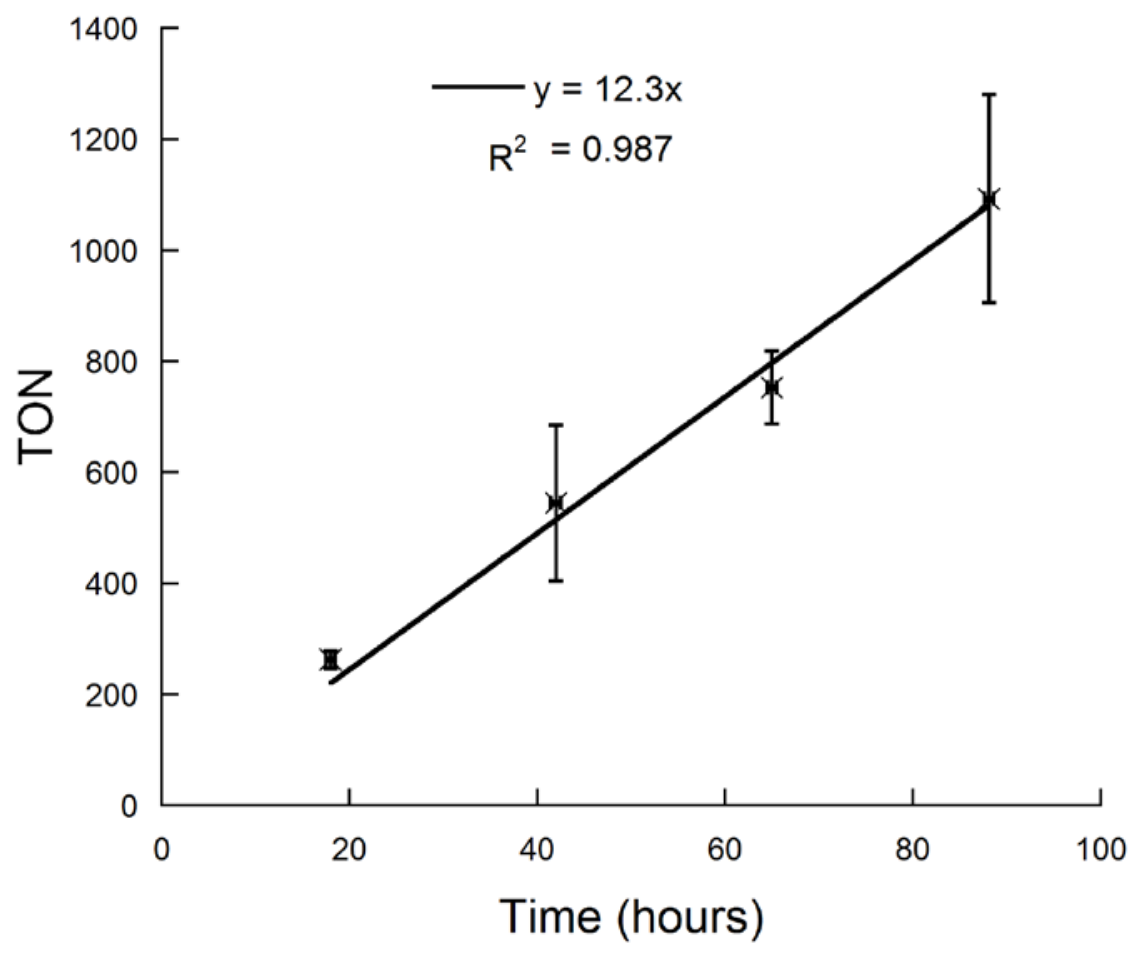

Figure S4. Time course for ethyl acetate hydrogenation. Reactions conducted using $2 \mathrm{mM}$ catalyst 1 in neat ethyl acetate at 30 bar $\mathrm{H}_{2}$ and $120^{\circ} \mathrm{C}$. Catalyst order experiments run for $18 \mathrm{~h}$ to be within this initial rate regime. 


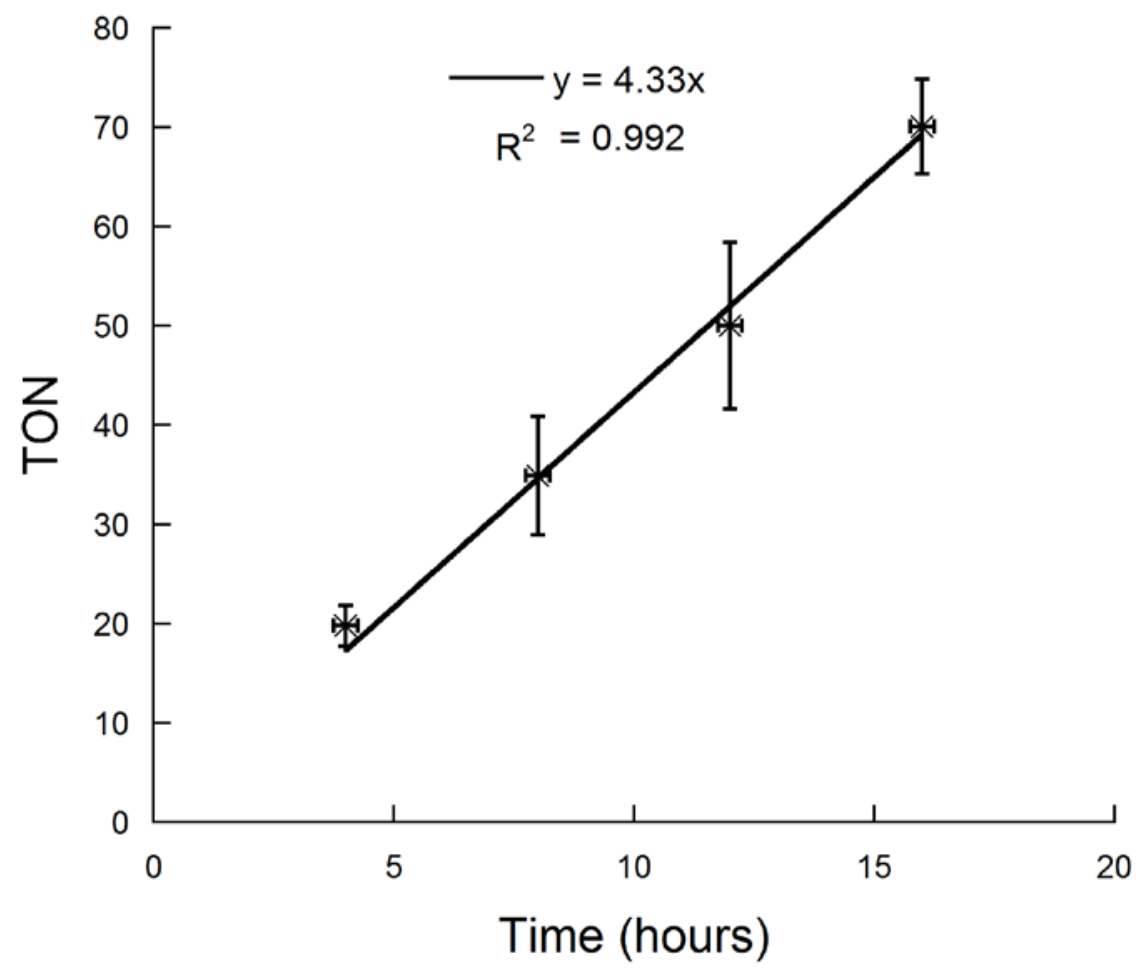

Figure S5. Time course of hexyl formate hydrogenation in DME solution. Reactions conducted using $0.321 \mathrm{M}$ hexyl formate and $2 \mathrm{mM}$ catalyst 1 in DME at 60 bar $\mathrm{H}_{2}$ and $100{ }^{\circ} \mathrm{C}$. Substrate order experiments run for $4 \mathrm{~h}$ to be within this initial rate regime.

\section{References}

1 Pangborn, A. B.; Giardello, M. A.; Grubbs, R. H.; Rosen, R. K.; Timmers, F. J. Organometallics 1996, 15, 1518.

2 Ogo, S.; Kabe, R.; Hayashi, H.; Harada, R.; Fukuzumi, S. Dalton Trans. 2006, 4657.

3 Ogo, S.; Makihara, N.; Kaneko, Y.; Watanabe, Y. Organometallics 2001, 20, 4903.

4 Brewster, T. P.; Miller, A. J. M.; Heinekey, D. M.; Goldberg, K. I. J. Am. Chem. Soc. 2013, 135, 16022.

5 Williams, D. E.; Peters, M. B.; Wang, B.; Roitberg, A. E.; Merz, K. M. J. Phys. Chem. A 2009, 113, 11550.

6 Dzudza, A.; Marks, T. J. Org. Lett. 2009, 11, 1523.

7 Spectral Database for Organic Compounds (SDBS); 1H NMR spectrum; SDBS No.: 10291; RN 592-

90-5; http://riodb01.ibase.aist.go.jp/sdbs/ (July 1, 2014).

8 Olah, G. A.; Fung, A. P.; Malhotra, R. Synthesis 1981474.

9 In Purification of Laboratory Chemicals (Fifth Edition); (Eds: Armarego, W.L.F.; Chai, C.L.)

Butterworth-Heinemann: Burlington, 2003, p 80.

10 Fulmer, G. R.; Miller, A. J. M.; Sherden, N. H.; Gottlieb, H. E.; Nudelman, A.; Stoltz, B. M.; Bercaw, J. E.; Goldberg, K. I. Organometallics 2010, 29, 2176.

11 Elders, N.; Schmitz, R. F.; de Kanter, F. J. J.; Ruitjer, E.; Groen, M. B.; Orru, R. U. A. J. Org. Chem. 2007, 72, 6135.

12 Porcheddu, A.; Giacomelli, G.; Piredda, M.; Carta, M.; Nieddu, G. Eur. J. Org. Chem. 2008, 5786. 